\title{
Study of the swelling deformation characteristics of red clay
}

\author{
Kai sheng Chen ${ }^{1,2, a *}$, Ze hua $\mathrm{Wu}^{2, \mathrm{~b}}$,Zhen $\mathrm{Lu}^{2, \mathrm{c}}$ \\ School of Civil Engineering, Guizhou University Guizhou Guiyang China \\ achen_kaisheng@163.com,,1085451862@qq.com, 'Lu_zhenqiaosui@163.com
}

\begin{abstract}
Key words: red clay, expansion deformation, expansion rate
Abstract::The paper is aimed at the phenomenon of red clay subgrade disease,taking the subgrade filling from the Yuqing-Kaili Expressway as the research object,doing the expansion test on the red clay,analysing of red clay expansion deformation law. The results showed that in the same compaction degree, different initial moisture content, the expansion rate of the sample with the optimum moisture content is minimum. And in the same initial moisture content, different compaction degree, the sample of high compaction degree has the small expansion quantity. The absolute expansion rate gradually increases with the expansion time, relative expansion rate decreases with the expansion time. That is the sample's speed of expansion is very high in $30 \mathrm{~min}$ after the start, then the speed of expansion will slow down.
\end{abstract}

\section{Foreword}

Because the red clay has high moisture content, high plasticity, high void ratio and other special engineering properties, the red clay project achieve design goal during the period of the construction, with the operation time of the highway growing, the slope begin sliding and the pavement begin cracking. The primary cause is the degradation of strength properties of red clay filling under the action of wetting-drying cycles and repeated traffic load,the strength of the soil is gradually reduced, the stability of the soil is decreased, and the failure of the subgrade is eventually caused.Therefore, it is of practical significance to study the law of red clay expansion for the road construction in red clay areas.

\section{Basic physical properties of Red clay}

This experiment adopted by the soil samples taken from Yuqing - Kaili Expressway twelfth section . Soil characteristics as follows: brownish red, wet, the homogeneous soil, the compact structure, w ith certains small wormholes and the wholes of plant roots. On the grain composition, most is the sil ty clay. According to the road test procedures (JTG E40-2007) method ${ }^{[5]}$, the basic physical properti es of the soil is shown in table 1.

Table1 Basic physical properties of red clay

\begin{tabular}{|c|c|c|c|c|c|}
\hline \multirow{2}{*}{ JTG E40-2007 } & $>0.075 \mathrm{~mm} / \%$ & \multicolumn{2}{|c|}{$0.074 \sim 0.002 \mathrm{~mm} / \%$} & \multicolumn{2}{|c|}{$<0.002 \mathrm{~mm} / \%$} \\
\cline { 2 - 6 } & 17.25 & \multicolumn{2}{|c|}{71.41} & \multicolumn{2}{|c|}{11.34} \\
\hline $\begin{array}{c}\text { Optimum } \\
\text { moisture } \\
\text { content/\% }\end{array}$ & $\begin{array}{c}\text { Maximum } \\
\text { dry unit weight } \\
\mathrm{g} / \mathrm{cm}^{3}\end{array}$ & $\begin{array}{c}\text { Plastic } \\
\text { limit/\% }\end{array}$ & $\begin{array}{c}\text { Liquid } \\
\text { limit/\% }\end{array}$ & $\begin{array}{c}\text { Coefficient } \\
\text { of } \\
\text { nonuniformity }\end{array}$ & $\begin{array}{c}\text { Coefficient } \\
\text { of } \\
\text { graduation }\end{array}$ \\
\hline 37.2 & 1.46 & 38 & 59 & 9.38 & 1.6 \\
\hline
\end{tabular}




\section{Testing Program}

\section{Sample Preparation}

Using the proctor compaction test to make the 20 groups of soil samples with a certain moisture content and a certain degree of compaction, the samples shown in table 2

Table2 Sample preparation

\begin{tabular}{|c|c|c|c|c|}
\hline $\begin{array}{c}\text { Moisture } \\
\text { content/\% }\end{array}$ & \multicolumn{4}{|c|}{ Degree of Compaction/\% } \\
\hline 30 & 75 & 85 & 90 & 96 \\
\hline 34 & 75 & 85 & 90 & 96 \\
\hline 37.2 & 75 & 85 & 90 & 96 \\
\hline 40 & 75 & 85 & 90 & 96 \\
\hline 44 & 75 & 85 & 90 & 96 \\
\hline
\end{tabular}

\section{Test Method}

Put the prepared sample into water, measure the height of the sample at different time after expansion. The absolute expansion rate and relative expansion rate are calculated by the following formula.

a.Absolute expansion for i text $\square_{a i}$.

$$
\square_{a i}=\frac{z_{i}-z_{0}}{z_{0}} \times 100 \%
$$

In the formula: $\mathrm{z}_{i}$ is the height of sample for $\mathrm{i}$ text $(\mathrm{mm}) ; \mathrm{z}_{0}$ is the initial height of sample(mm). If the absolute value of the number is bigger, it means the amount of expansion is bigger.

b. Relative expansion for i text $\square_{r i}$.

$$
\square_{r i}=\frac{\mathrm{Z}_{\mathrm{i}}-z_{i-1}}{\mathrm{Z}_{\mathrm{i}-1}} \times 100 \%
$$

In the formula: $\mathrm{z}_{i}$ is the height of sample for $\mathrm{i}$ text $(\mathrm{mm}) ; \mathrm{z}_{i-1}$ is the height of sample for $\mathrm{i}-1$ text $(\mathrm{mm})$. If the absolute value of the number is bigger, it means thespeed of expansion is higher.

\section{Experiment Result}

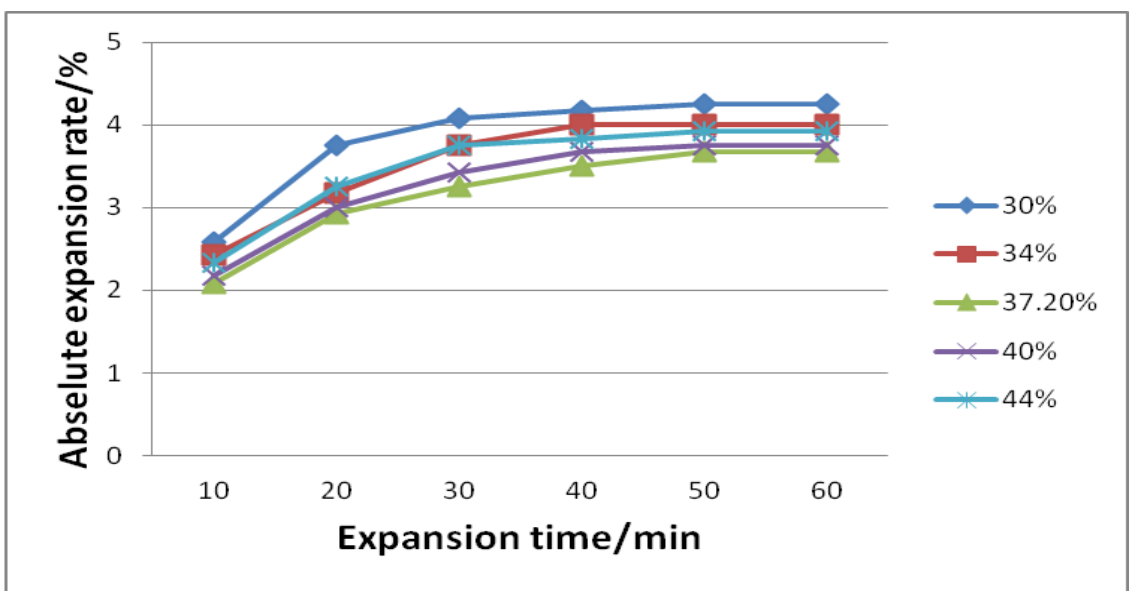

Fig.1 K=75\% Relationship between absolute expansion rate and expansion time 


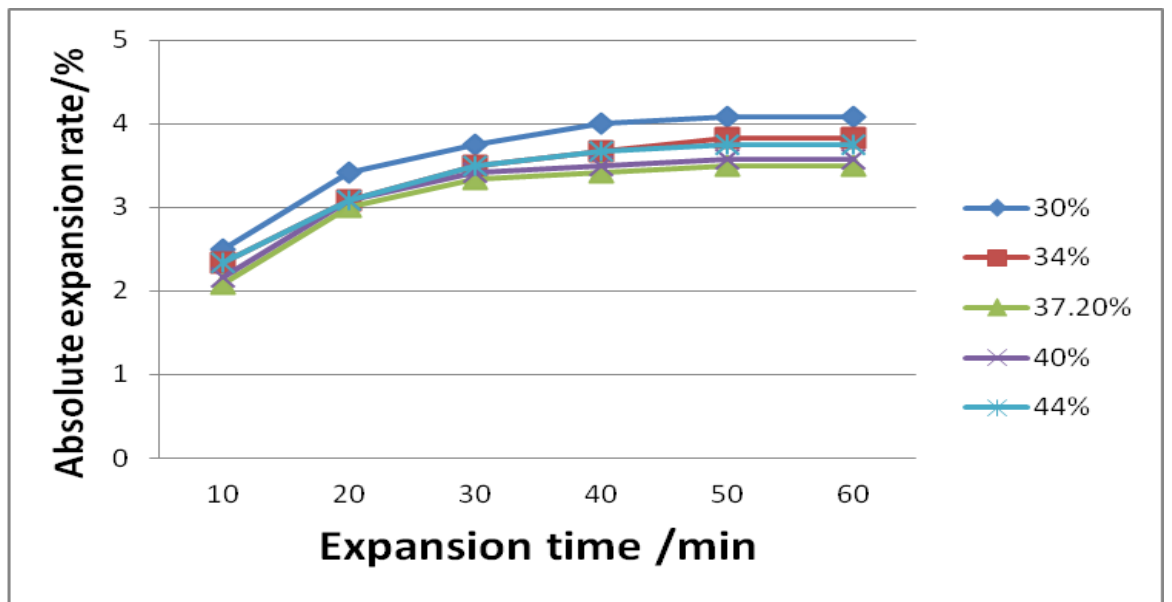

Fig.2 K=85\% Relationship between absolute expansion rate and expansion time

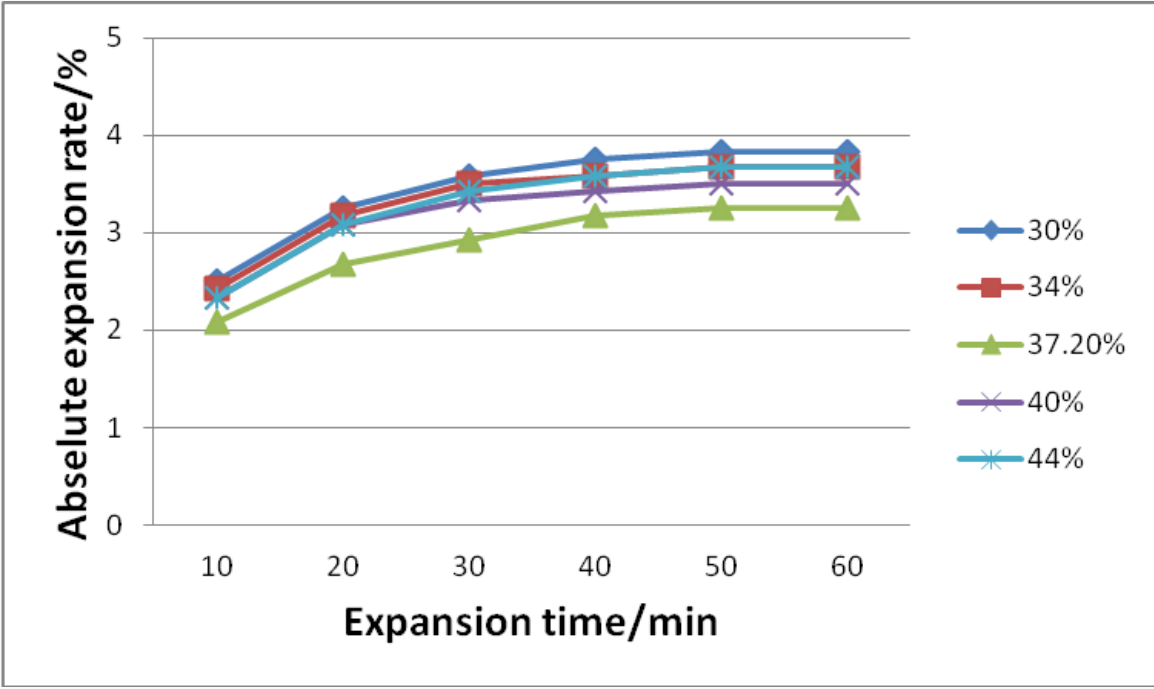

Fig.3 K=90\% Relationship between absolute expansion rate and expansion time

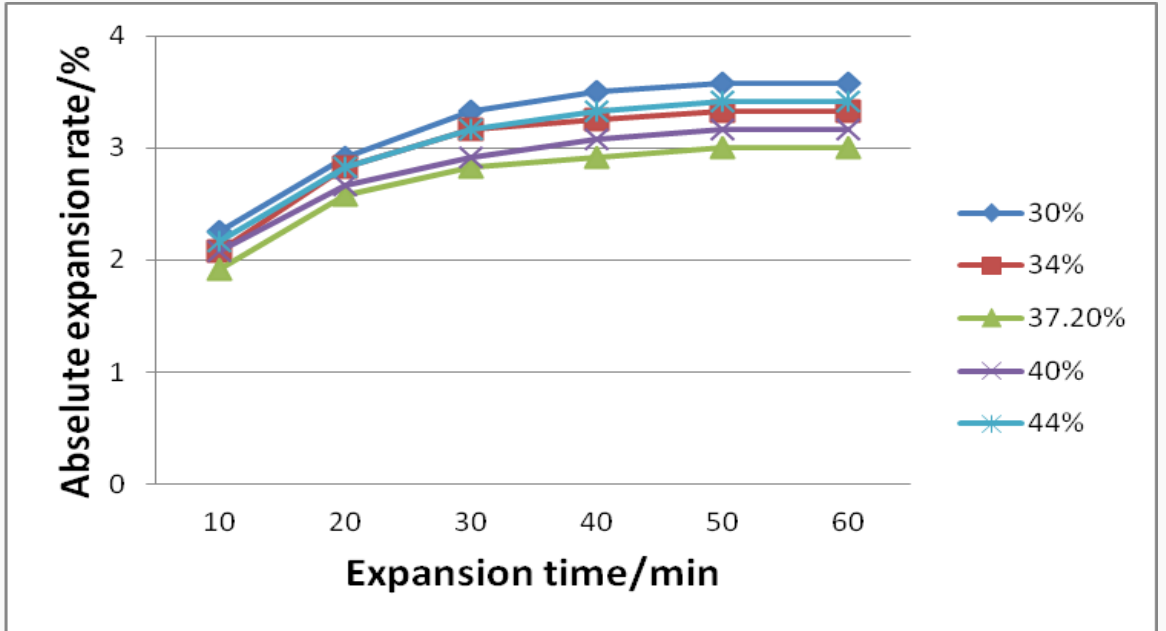

Fig. $4 \mathbf{K}=96 \%$ Relationship between absolute expansion rate and expansion time 


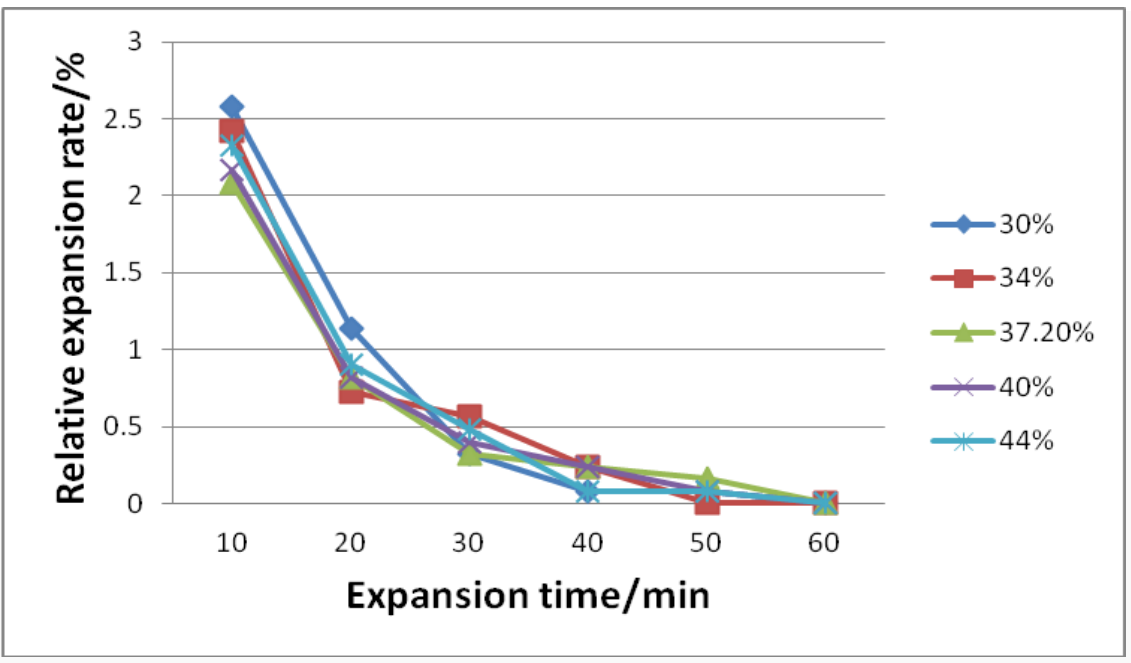

Fig. 5 K=70\% Relationship between relative expansion rate and expansion time

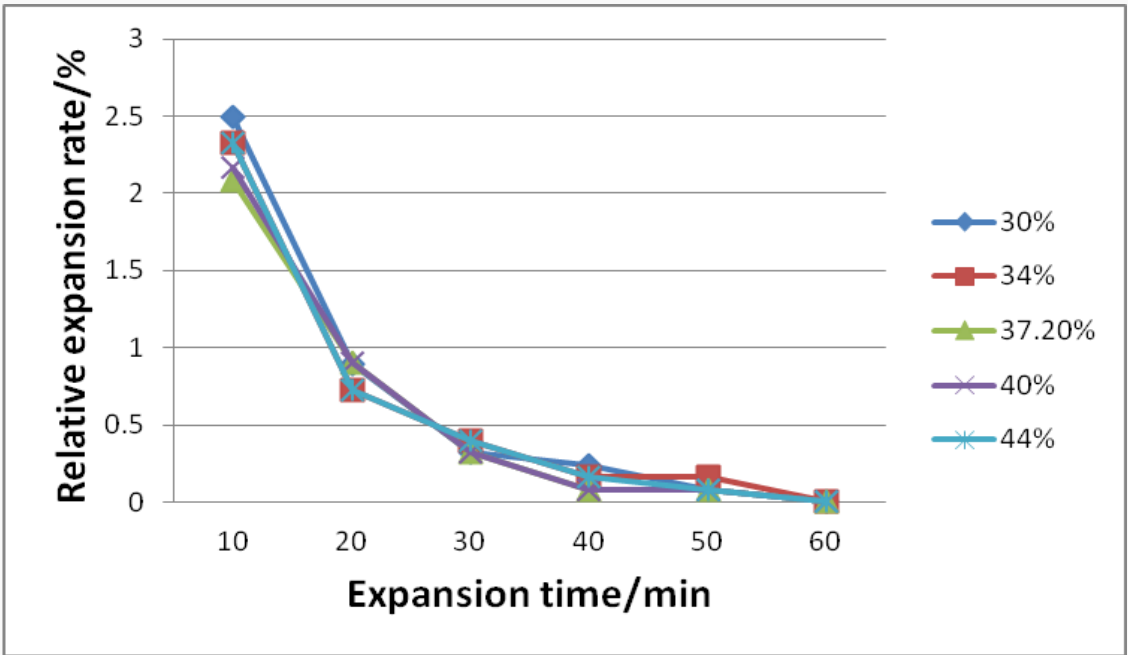

Fig. 6 K=85\% Relationship between relative expansion rate and expansion time

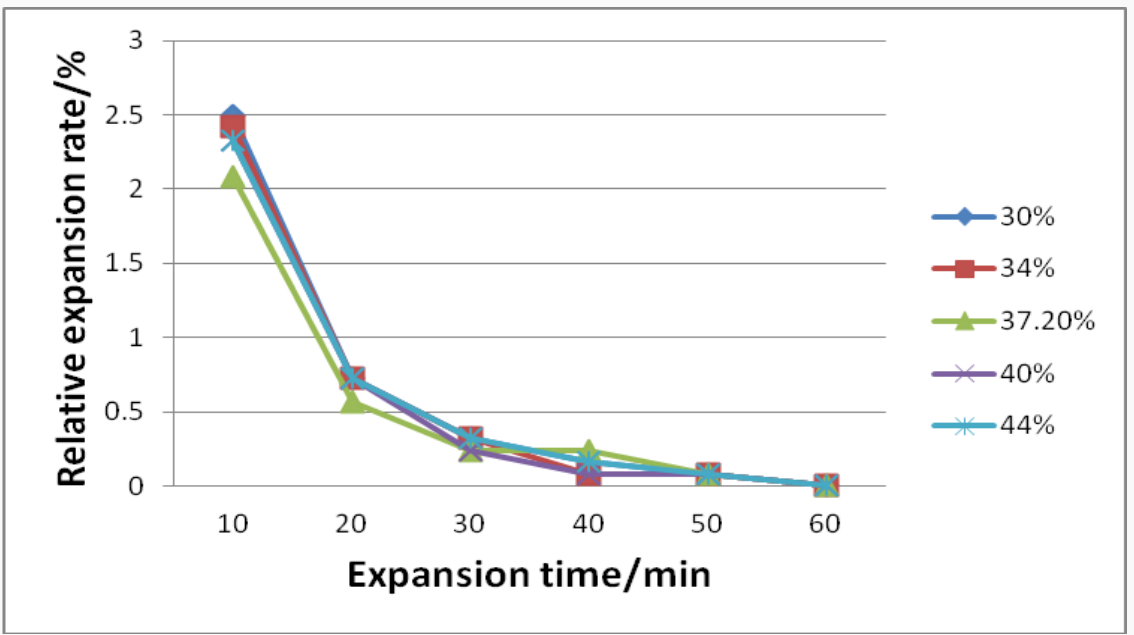

Fig.7 K=90\% Relationship between relative expans ion rate and expansion time 


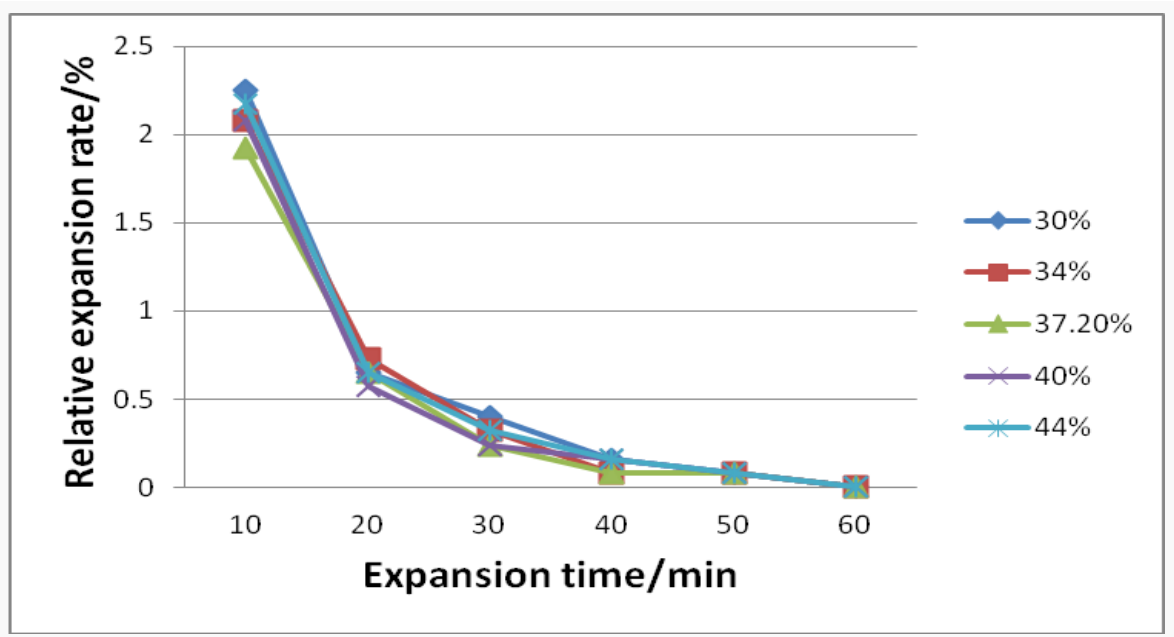

Fig. 8 K=96\% Relationship between relative expansion rate and expansion time

\section{Conclusion}

(1) In same compaction degree, different initial moisture content, the expansion rate of the sample with the optimum moisture content is minimum. And in same initial moisture content, different compaction degree, the sample of high compaction degree has the small expansion quantity.

(2)The absolute expansion rate gradually increases with the expansion time, relative expansion rate decreases with the expansion time. That is the sample's speed of expansion is very high in $30 \mathrm{~min}$ after the start, then the speed of expansion will slow down.

\section{Acknowledgment}

This paper is supported by the National Natural Science Foundation of China (51368010), the joint fund project between The Science and Technology Department of Guizhou Province and Guizhou University (Qiankehe LH Zi[2014]7663).

\section{References}

[1] Test Methods of Soils for Highway Engineering.(JTG E40-2007)

[2] Zhihong Huang,Lijun Zhu, Yiling Liao.Mechanical Properties Of Red Clay Under Different Stress Paths[J]. Journal of Rock Mechanics and Geotechnical Engineering, 2004，23(15):2599-2603

[3] Longwu Liu,Heping Yang,Shilei Kang.etal.Research on Nature of Red-Clay-Filling Material Used in Road.[J]. HIGHWAY,2002(6):125-128

[4] Kaisheng Chen, Yuan Yin.Experimental Research of Strength Index of Red Clay for Guiyang-Qingzhen Expressway [J]. Journal of Highway and Transportation Research and Development, 2011, 28(3) : 61-66

[5] Qingtao Bi, Guoping Jiang, Shuyun Ding.WATER CONTENT INFLUENCE ON THE SHEARING STENGTH ON RED CLAY[J].Journal of Earth and Environment， 2005，33(3):144-147 